\title{
The Body-ScanFIT® System: The Importance of Population's Classification into Morphological Families and of Anthropometric Mannequins in Apparel and Ergonomics
}

\author{
Gianni SERENI*, Leonardo FRANCESCHIa \\ Cad Modelling Ergonomics srl, Florence, Italy
}

\section{Introduction}

Clothing manufacturing companies are getting more and more interested in understanding how their customers are changing.

SME and big apparel companies have realized how it's important to produce according to actual data highlighting the shape of the body: no more a mere concept of "size", but volume and circumference of customers.

In the last 20 years, due to many reasons such as immigration, economic crisis and a more sedentary life, significant demographic changes have affected people's body shape.

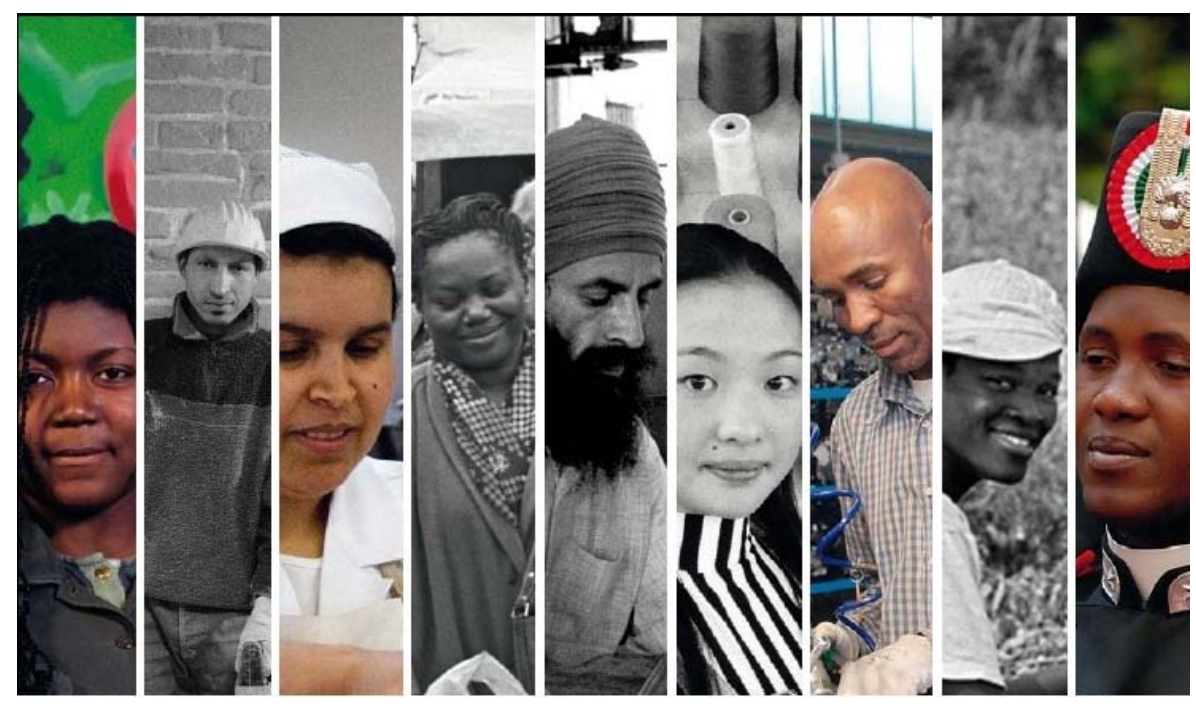

Fig.1. "Our melting pot society".

Cad Modelling Ergonomics, with more than 40 years of experience in anthropometry applied to textile - apparel industry and ergonomics, by its 3D body scanning technologies helps identifying such changes in population.

FORMAX ${ }^{\circledR}$, the anthropometric mannequins developed as the natural result of the Theory of the Body Shapes $^{\odot}$ (copyright SIAE of Cad Modelling Ergonomics num.94018), act as the right tool to guarantee the perfect fit, volume, comfort and safety to garments and ergonomic devices as they are built on real average body shapes worldwide.

\footnotetext{
*Email press@cadmodelling.it Tel.+39 0552476261/2 www.cadmodelling.it

a Email leonardo.franceschi@cadmodelling.it Tel. +39 0552476261/2 www.cadmodelling.it
} 


\section{Theory of Body-Shapes ${ }^{\odot}$}

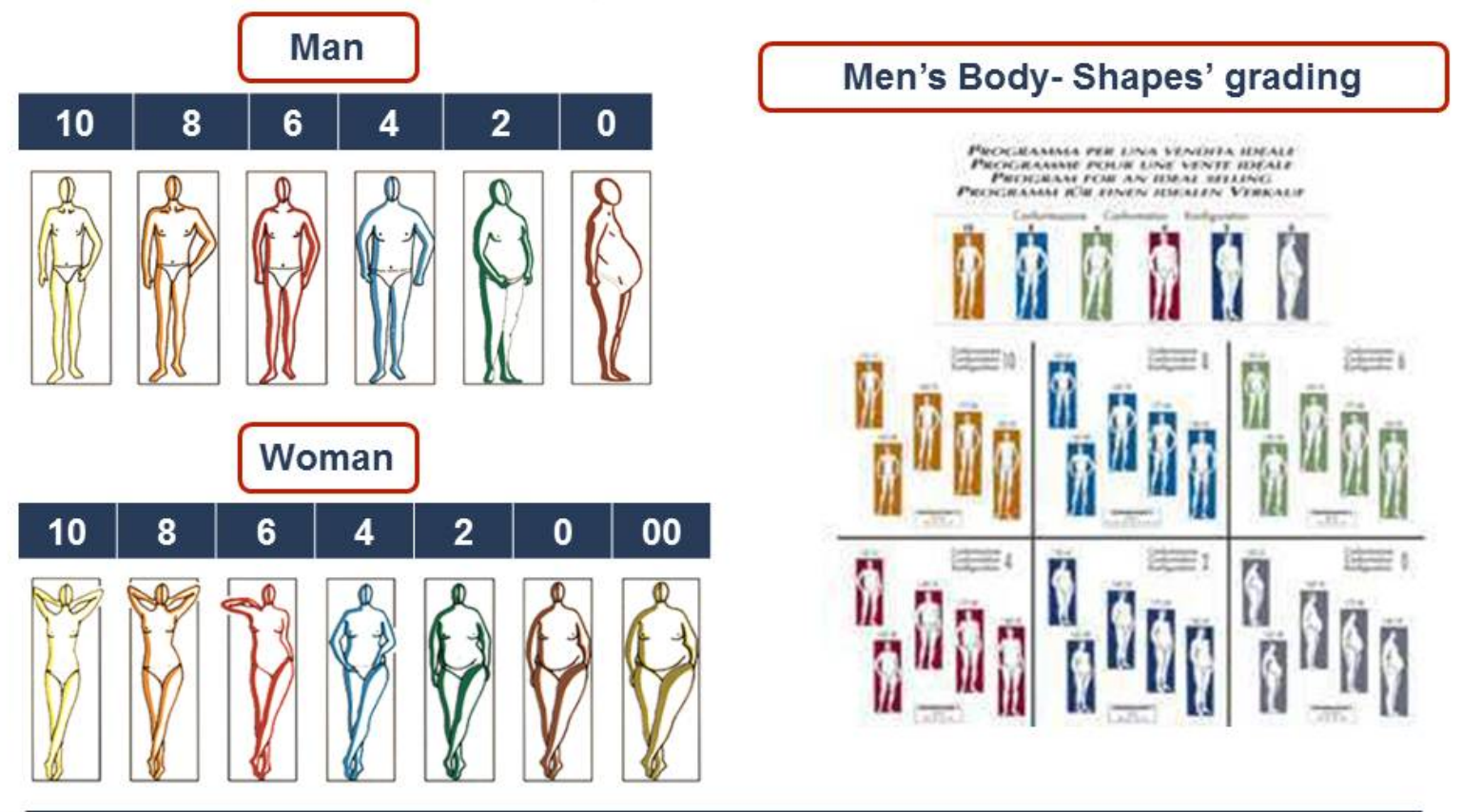
CadModelling

Fig. 2. Theory of Body Shapes chart.

The paper will focus on the importance for apparel producers to base their collections on real collected anthropometric data of population by the use of Body-ScanFIT® system.

\section{Cad Modelling Ergonomics' experience}

For ten years now, a CEN European Community working group TC248, the WG10, made up of international experts, is focusing its attention on a new size designation of clothes based on anthropometric measures. Given the fact that the old system based on size concept is not reliable for clothing market and customers, the aim is to use a common language to designate the different sizes with a single code. The solution will be the introduction of a new European labeling system that takes into account volume, height and shape of population.

Since 2005, Cad Modelling Ergonomics is the Italian party expert of the above mentioned European working group at CEN on Norm EN 13402 "Size Designation of Clothes". Capitalizing on this important position, company participates to national and international meetings representing the Italian official position. Furthermore, thanks to the continuous monitoring of Italian and European demographic changes by 3D body scanning technologies and surveys, Cad Modelling Ergonomics is one of the leading experts in the field. 


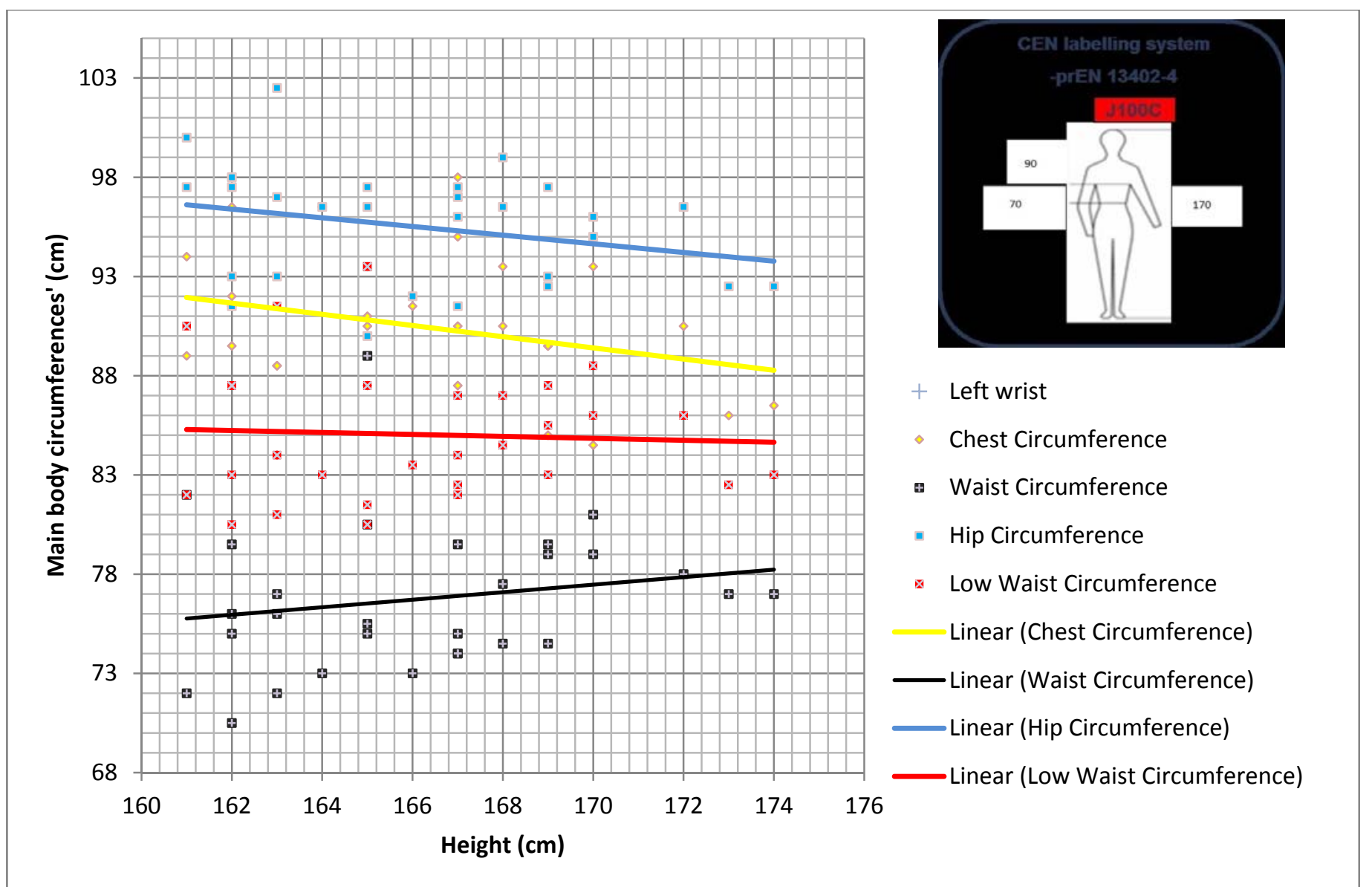

Fig.3. Main body circumferences' grading following height in woman body shape 7.

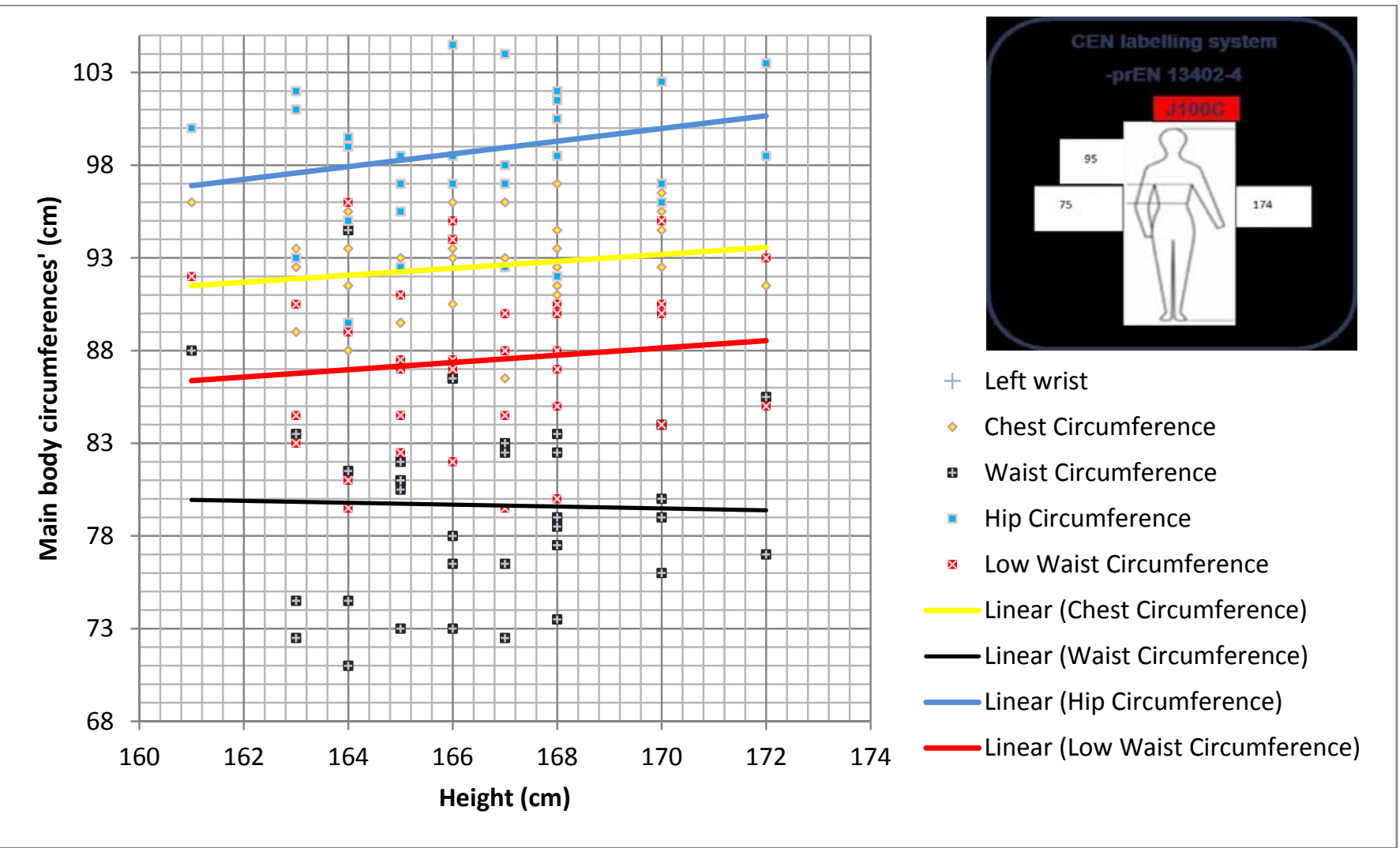

Fig.4. Main body circumferences' grading following height in woman body shape 5. 
The real added value brought by Cad Modelling Ergonomics is the concept "body volume": body shapes are more reliable for apparel producers than linear measures and can represent the reference parameter which to set the collection on.

\section{Body-ScanFit ${ }^{\circ}$ system: the only portable 3D body scanner in the world}

Constantly pushing the technology boundaries further, Cad Modelling Ergonomics developed Body$\mathrm{ScanFit}^{\circledR}$, a patented Anthropometric Classification System, composed of a revolutionary and unique portable body-scanner, validated by ENEA, an Italian primary research institute. The system allows scanning any human body in few seconds, and classifying it in the proper Morphological Family (also reproduced in Formax ${ }^{\circledR}$ ) to transmit data to the product pipeline.

Body-ScanFit ${ }^{\circledR}$ is based on the first real portable and non intrusive body scanner that fits inside a standard dimensions suitcase. It's easy to set up and user-friendly.

Through just 4 seconds scanning, it assures precision and accuracy, providing data that can be used for several applications. Body-ScanFit ${ }^{\circledR}$ comprehends:

- A unique portable 3D body scanner

- A software for measurements extraction

- A proprietary software for anthropometric classification, the FX-FIT, that highlights the fitting needs of any scanned body and classifies it into the proper body shape.

- Formax® Anthropometric mannequins

\section{Customization in data analysis as further key to success:}

Collected data can be highly customizable, since they can be analyzed in different charts following company targets: manufacturers have the opportunity to perform any type of analysis to better understand their customers' needs and expectations.

FX-FIT software can be customized on company's requirements using CME experience for matching existing size systems and charts with real body shapes (fitting sessions on Formax $®$ required), thus allowing apparel companies to sell online/ supply Corporate wear, avoiding stocks or returns

Hereafter some examples of customized data analysis:

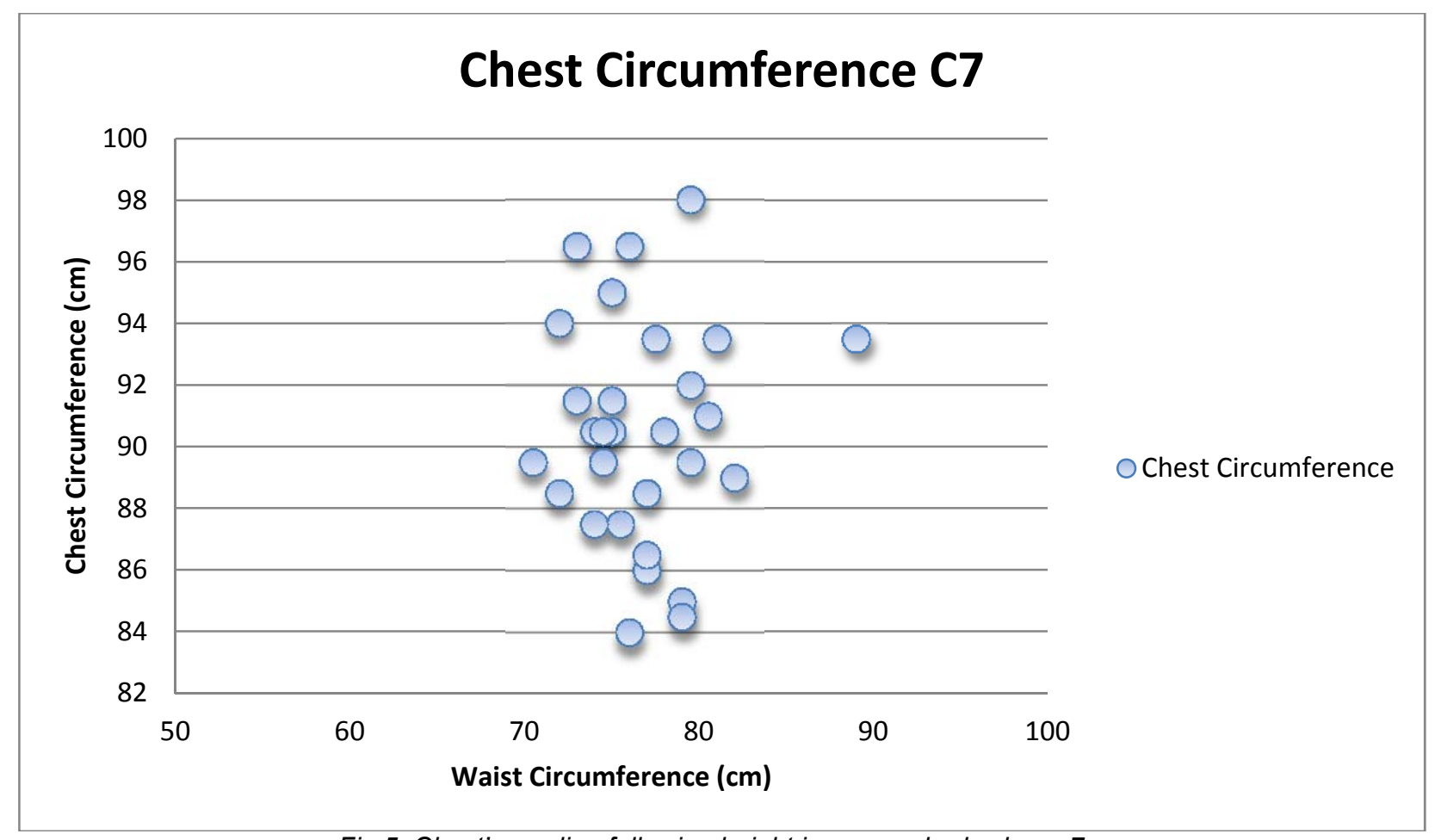

Fig.5. Chest's grading following height in woman body shape 7. 


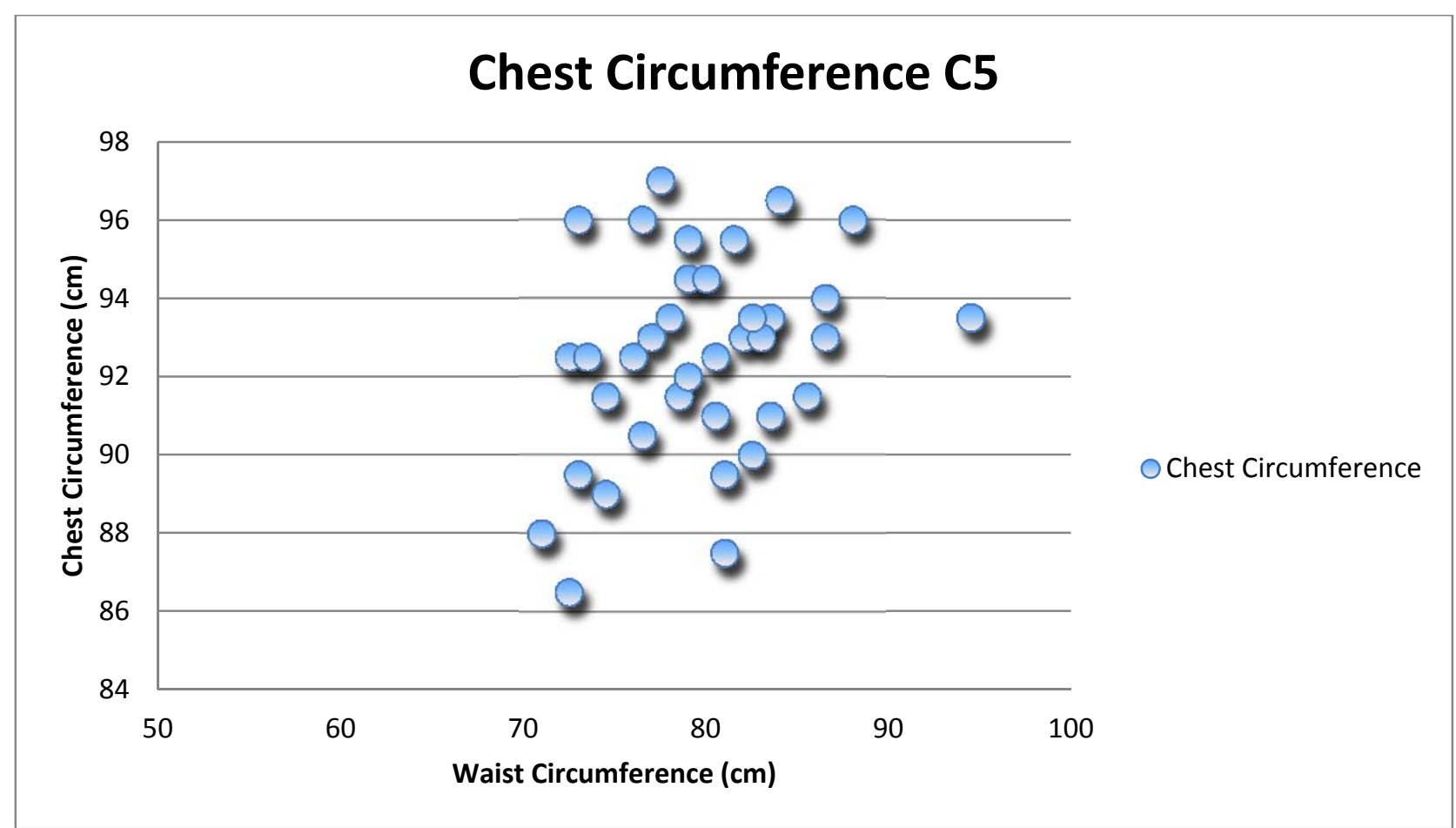

Fig.6. Chest's grading following height in woman body shape 5.

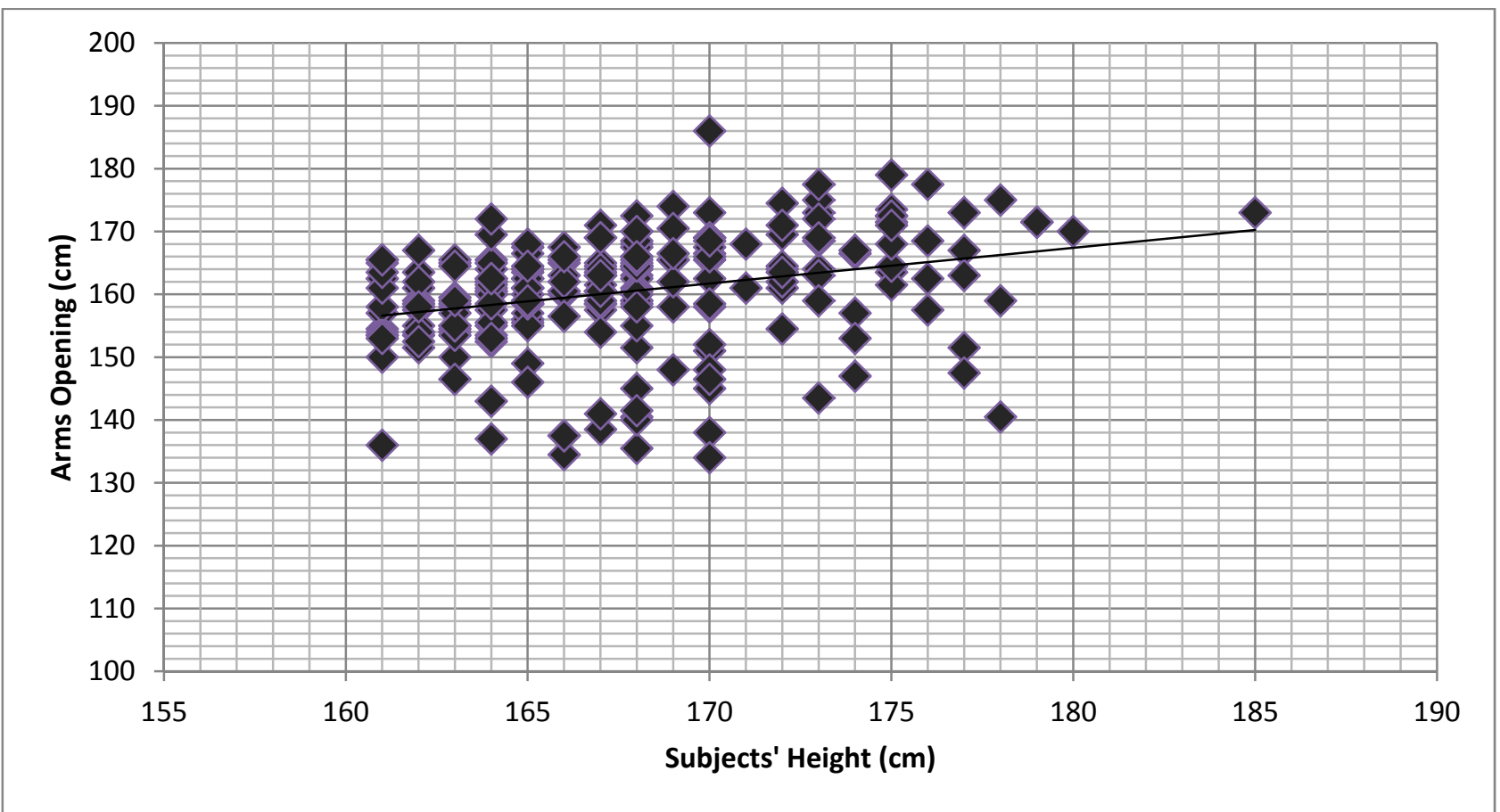

Fig.7. An example of data analysis that can be performed by Fx-FIT software: the arms opening corresponding to height among the scanned subjects. This kind of correlation was already studied by Leonardo da Vinci. 


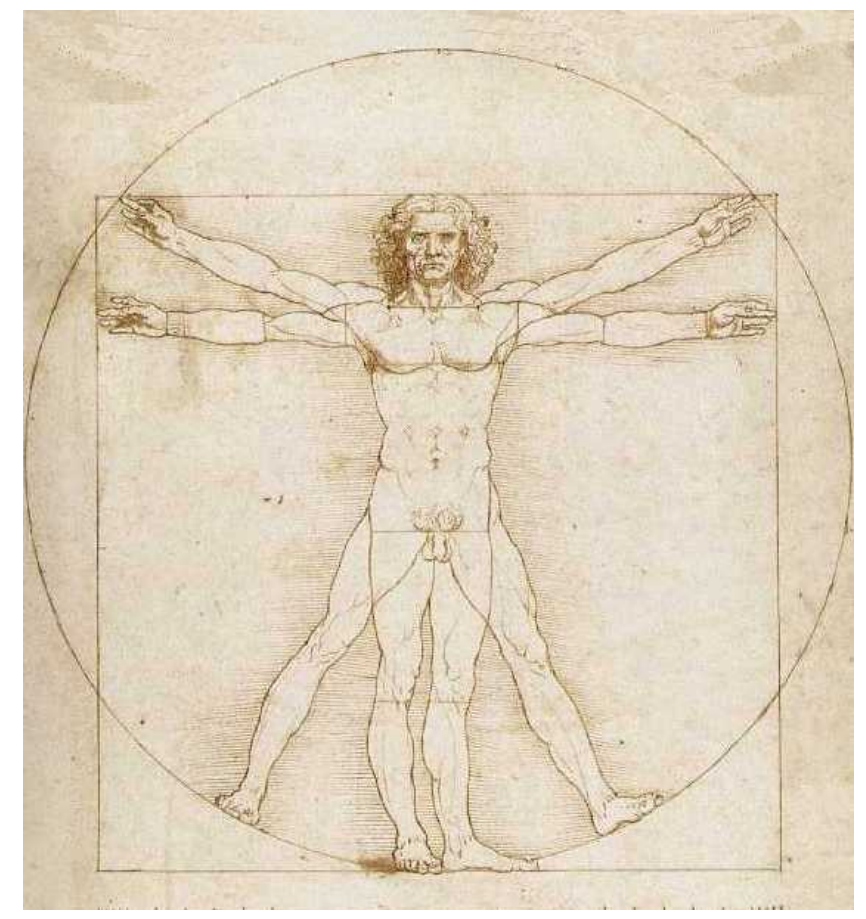

Fig. 8 Leonardo's Vitruvian man.

\section{Body Shapes Identification}

The classification procedure includes the following steps:

- Scan of the subject and point cloud creation

- Linear measurements extraction

- Classification into the most suitable morphological family by FX-FIT software

- Identification of the corresponding FORMAX ${ }^{\circledR}$ mannequin for the upper and lower part of the body

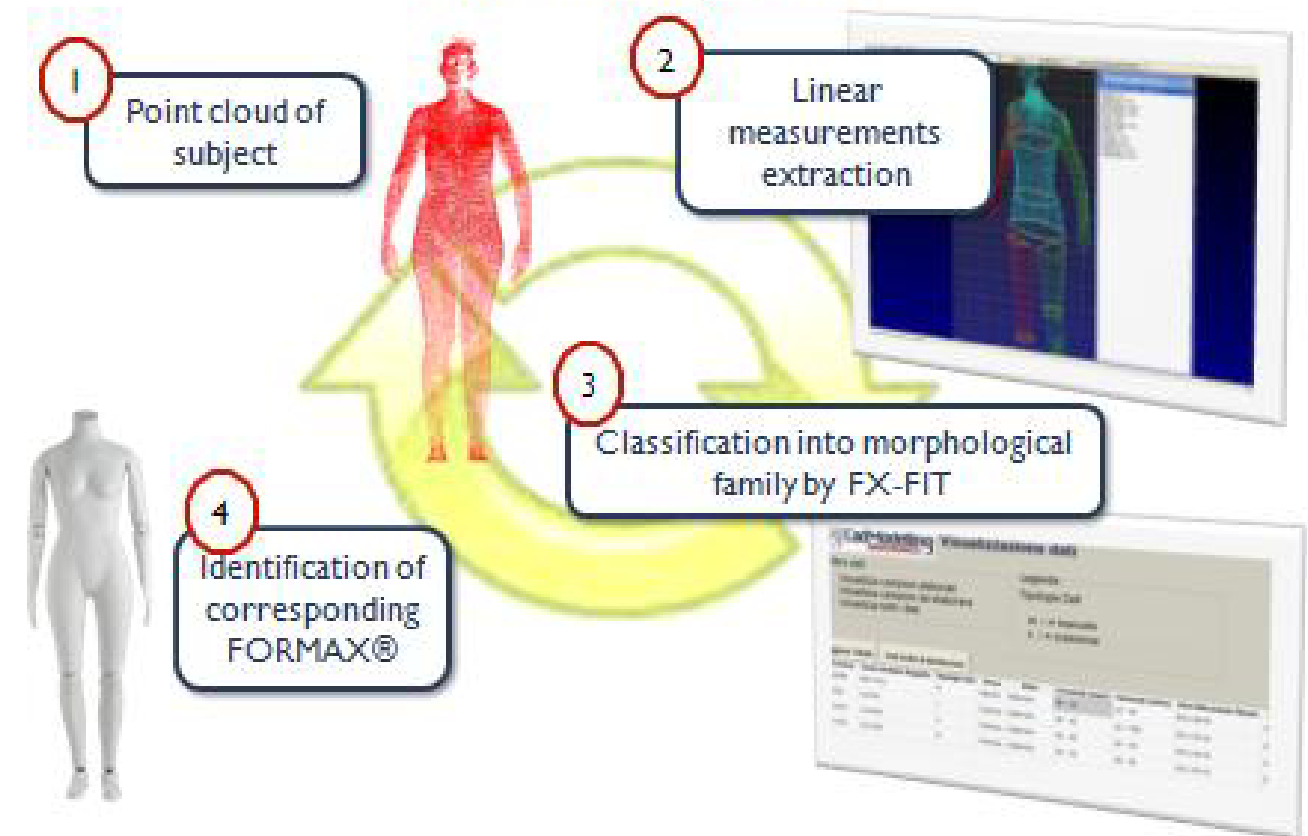

Fig. 9. "Survey procedures". 
An important anthropometric survey was done by the company in 2010 on a representative sample of women from 18 to 35 years on Italian territory: this study revealed the new percentage distribution of body shapes and allowed to find out the most recurrent body shapes in the country. Cad Modelling Ergonomics can also rely on its historical anthropometric database, collected since 1960 and constantly updated.

After the latest updates, the results obtained allow the company to confirm the accuracy of the current Formax $\circledast$ anthropometric mannequins' body shapes and increase database adding new morphotypes.

\section{Theory of Body Shapes ${ }^{\odot}$}

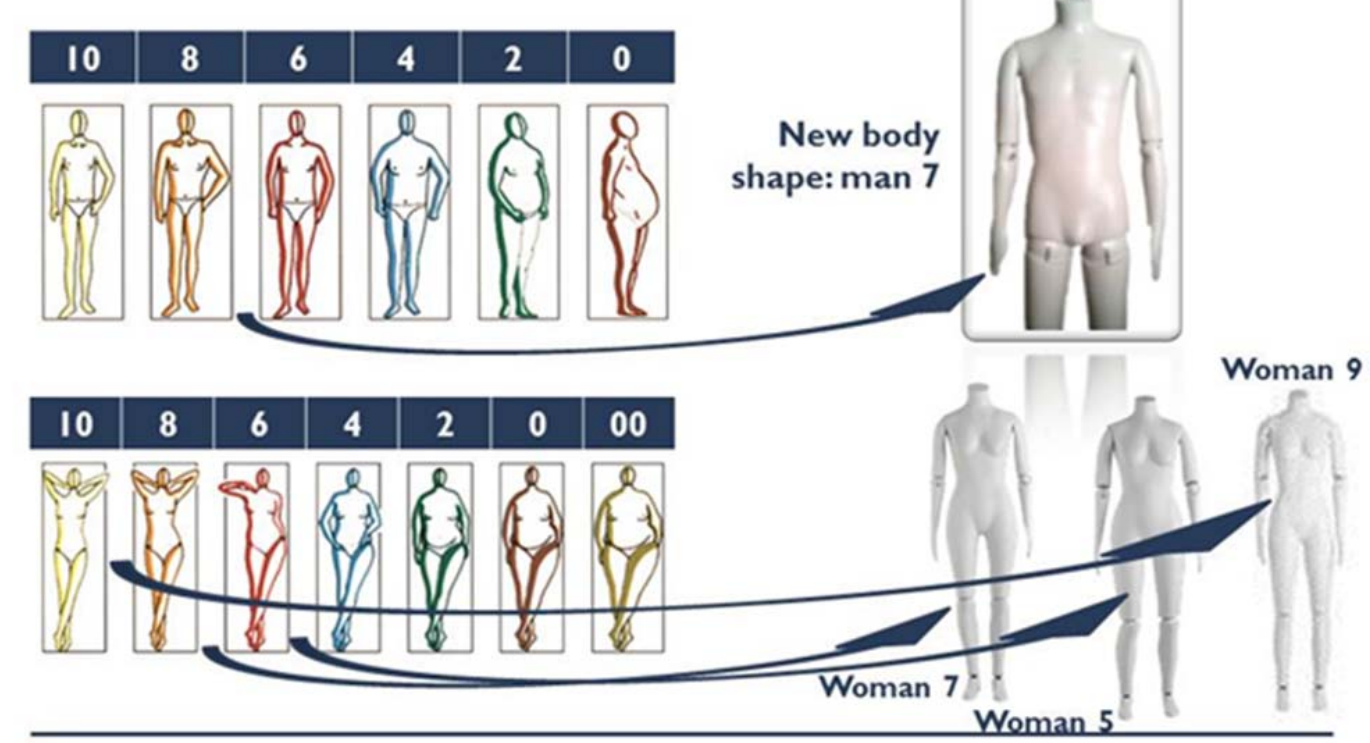

CadModelling

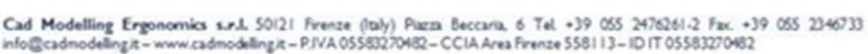

Fig.10. New Body shapes added.

\section{Cad Modelling Ergonomics' Formax@}

Cad Modelling Ergonomics, constantly conducting anthropometric surveys along the European territory and exploiting the extensive know how in anthropometrics, developed the fit apparel mannequins Formax $®$, dummies for fitting activities of garments and design of ergonomic products. As population is constantly changing, the Theory of Body Shapes $\odot$ offers the solution in terms of starting point and grading rules. Thanks to recurring anthropometric surveys to constantly match real people, the morphological families are thus improved and updated.

Thanks to a recent collaboration with Institutes of sports medicine and sports clubs, Cad Modelling increased its children anthropometric database confirming the validity of its special products for overweight childrenswear manufacturers: the Formax® Plumpy, a full-body $134 \mathrm{~cm}$ tall mannequin in a special "plump" version. 


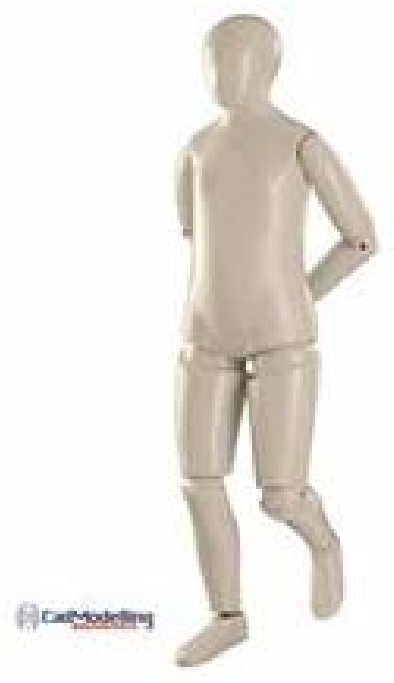

Fig.11. "Plumpy Formax®”.

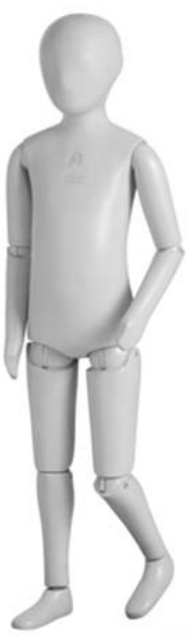

Fig.12. "Slim Formax®".

On the other hand, thanks to its partnership with Northern European Childrenswear manufacturers, CME designed a special Formax ${ }^{\circledR}$ Slim dedicated to that market area, where children are taller and slimmer respect to the rest of Europe.

That's also a the confirmation of the importance of mentioning the height on the childrenswear label, first, instead of the age.

\section{Conclusions: Mass Customization final steps and use of Formax ${ }^{\circledR}$ mannequins}

Garments manufacturers often create products on the basis of marketing analyses and statistics that do not fully match people's real volumes and body shapes. The process of data analysis is the key for the best mass customization choices (money saving) and the best results in terms of right fitting and comfort (final user's satisfaction).

FORMAX ${ }^{\circledR}$ are the only fit mannequins that guarantee the right fit, comfort, security to garments and ergonomic devices. Huge benefits in terms of unsold stocks decrease and improved customer's loyalty are some of the advantages producers can get.

Anthropometric mannequins FORMAX ${ }^{\circledR}$ allow to:

- Constantly check collection prototypes

- Get the right fit, comfort and volume of garments

- Correctly design ergonomic devices

- Test technical textiles in wind/rain tunnels or for flame/arc flash tests 

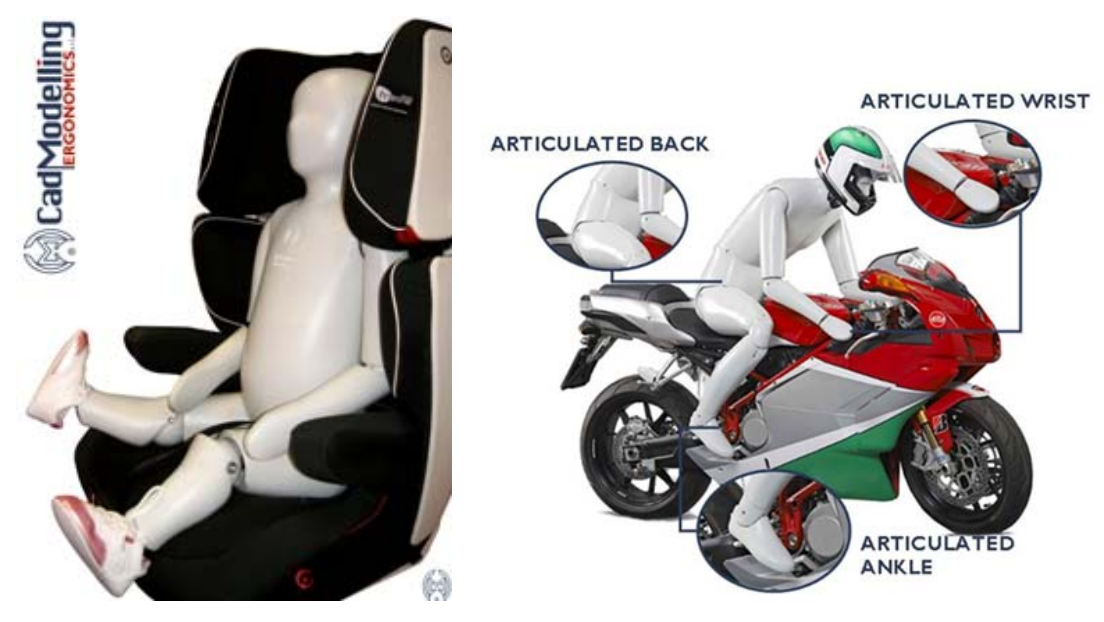

Fig.13. "Active and SuperActive FORMAX ${ }^{\circledR}$ for ergonomic and safety tests".

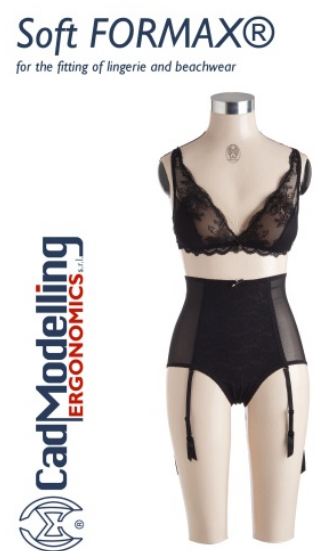

Fig.14. "Soft FORMAX ${ }^{(B)}$ for lingerie and beachwear producers.

The Theory of Body Shapes ${ }^{\odot}$ and FORMAX® are copyrights and patents of Cad Modelling Ergonomics srl. Any unauthorized use prohibited.

\section{Bibliography}

Quattrocolo S., METODO PER PROGETTISTI PER L'INDUSTRIA DELL' ABBIGLIAMENTO, Cad Modelling Ergonomics srl 1987

Quattrocolo S., ELECTRONIC IMAGING OF THE HUMANY BODY, CSEIAC, 1992

Cad Modelling Ergonomics srl, Theory of Body Shapes ${ }^{\odot}$ (Copyright $\odot$ SIAE ${ }^{\circ}$ 9401846)

Cad Modelling Ergonomics srl, patent EP1244367

Cad Modelling Ergonomics srl patent EP0634114B1 